at meetings of societies, patients submitted to operation by this method of mine,* and all who saw them were surprised by the amount of the power of extension which was thus secured. Mr. Steele, of the Bristol Infirmary, has both practised and published his approval of the method.

Fig. 1 shows a left arm immediately after the performance of the operation; the hook sustaining the structures which are to be carefully preserved.

\section{Fig. 2.}

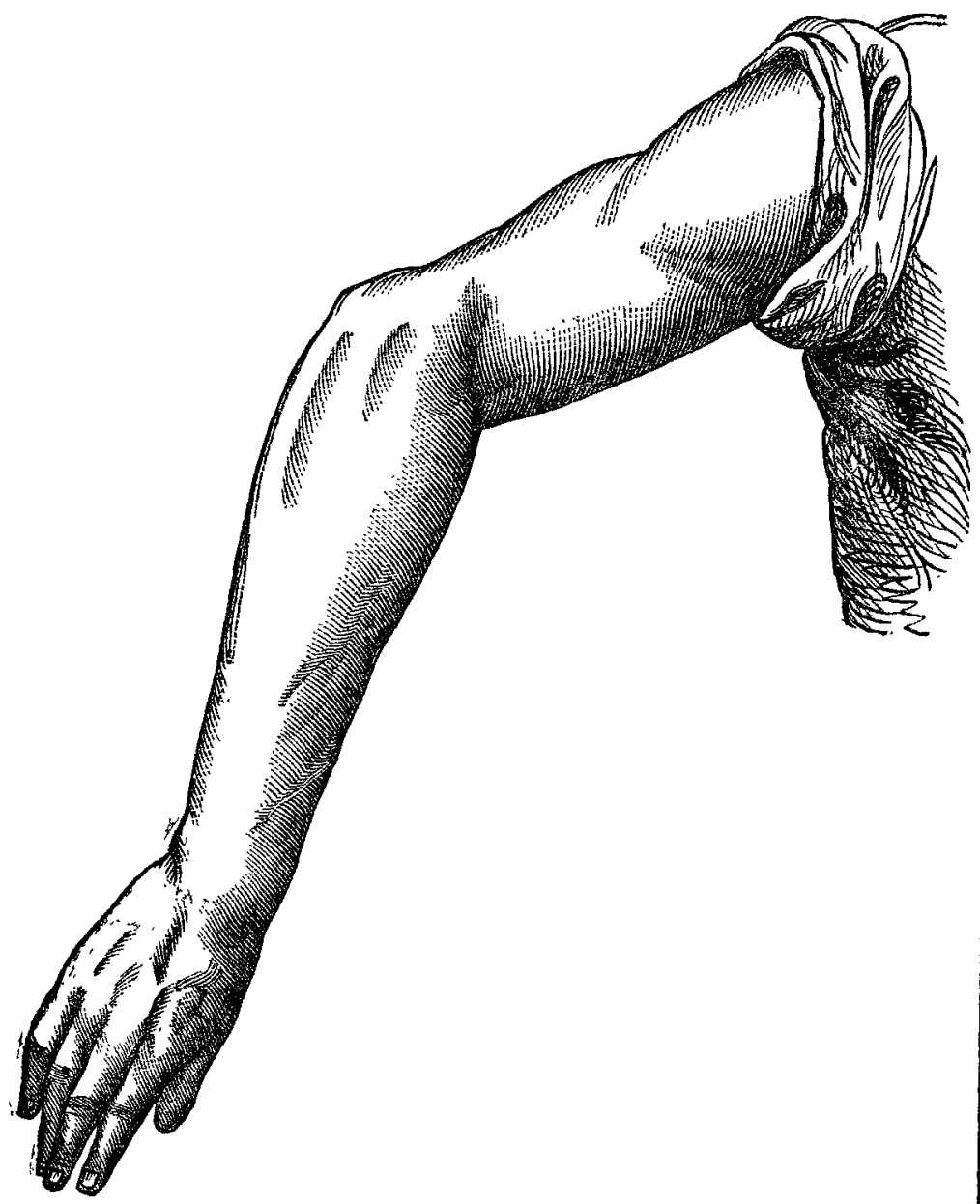

Fig. 2 is a sketch of the arm of J. N-, taken three years ago, and three years subsequent to operation. The forearm is in the position of active extension by the triceps. He could then play billiards, quoits, and use "the gloves" with facility.

Queen Anne-street, w.

\section{ON}

\section{FIFTY CASES OF HAMOPTYSIS TREATED WITH ERGOT.}

By JAMES M. WILLIAMSON, M.D. EDIN.,

RESIDENT MEDICAL OFEICER ROTAL TATTONAN HOSPTYAT FOF CONSUMPTION, VENTNOR; ISLA OF WIGH':

Aвour eighteen months ago; after reading the papers written on the subject by Dr. Anstie in the Practitioner, I commenced making a fair trial of the value of ergot in the treatment of hæmoptysis. The success which followed its administration was so encouraging that I gave-the drug in every case of hæmoptysis which I was: called upon to treat, and I now propose to state briefly the'results of its use in fifty cases.

The fifty patients were suffering from-phthisis in different stages, and the amount of the bømorrhage varied from abundant bright streaks on the sputa to the expectoration of several ounces of blood. As the cases all occurred in hospital practice, very little time was lost between the advent of the brmoptysis and the exhibition of the remedy. The ergot was invariably given by the mouth and in the form of the liquid extract. Much has been said about the

\footnotetext{
* Maunder's Operative Surgery, second edition, p. 120.
}

success of the subcutaneous injection of ergotin and its superiority to this plan, but since there was no diffeulty in any of the cases in administering a dranght, and as the drug acted in most instances with a promptitude which was sufficiently satisfactory, the hypodermic method was not employed. Forty-minim doses of the liquid extract may be given twice within the first hour, and, guided by the results, at least every two hours afterwards, the dose being diminisbed and given less frequently as the bæmorrhage subsides. I have never observed any disagreeable effect follow even upon the administration of large quantities within short periods, but, as a general rule, if four or five full doses make no distinct impression upon the bæmorrhage, the remedy should be abandoned for another. Care should be taken to use a fresh and sound preparation of the ergot.

Out of the 50 cases, the drug rapidly checked all bleeding in 44 instances. Of these 16 were women and $28 \mathrm{men}$, and in at least one-fourth of the number the hæmoptysis merited the term profuse. In 40 of the 44 cases it was the first and only remedy given; in 2 others it was successful after a mixture containing gallic acid, alum, and dilute sulphuric acid failed; in another it was effectual after acetate of lead with opium proved useless; while in the remaining instance it repressed the bleeding after both of these plans were unavailing. The ergot was ineffectual in 6 cases, and of these it may be well to give some particulars. Case 1 was that of a middle-aged widow, who had had several violent hæmorrhages. On this occasion it was very copious, and repeated doses of ergot, given in rapid successi, $n$, produced no perceptible abatement; gallic acid was then substituted, but just as it was making a decided impression it gave rise to such griping pains in the abdomen that it had to be given up; ergot was resumed, and the hæmorrhage rapidly ceased. Case 2 was that of a young man in whom the hæmoptysis was moderate; it was unaffected by ergot, but yielded to gallic acid. It is only right to add that in this case there was some doubt as to the goodness of the sample of ergot used. Cases 3 and 4 were two examples of a slight, but very chronic and obstinate hæmoptysis, in which the sputa had a uniform pink tinge. In one of the men, gallic acid succeeded after ergot proved a failure; in the other, gallic acid, ergot, acetate of lead with opium, perchloride of iron, ammonio-sulphate of iron, the mineral acids, and oil of turpentine, were all successively tried without avail. Case 5 was that of an unmarried woman, aged twenty-five. She had had many previous attacks. Ergot proved ineffectual, and was replaced with success by acetate of lead and opium. Case 6 was that of an unmarried woman, aged twenty-three, who had also had frequent previous hæmorrhages. On this occasion the bleeding was profuse, and resisted both ergot and gallic acid; oil of turpentine eventually subdued it.

The cases in which ergot failed have been stated somewhat fully, partly to show that, in at all events three of the number, it shared the failure in common with gallic acid, the remedy which is probably most frequently employed in the treatment of hæmoptysis. Over gallic acid ergot has the distinct advantages of never causing griping or constipation, and more especially of not interfering with a liberal use of milk. The large proportion-equivalent to 88 per cent.- of the cases in which ergot succeeded, not only testifies to its great value and claims for it our confidence, but also strongly justifies the recommendation that it should be the first drug tried in all cases of hæmoptysis. ventnor, I.W.

\section{CASE OF}

\section{COMPOUND FRACTURE OF THE PATELLA.}

\section{BY ARTHUR B. EWEN, M.R.C.S., \&C.}

THE case of Wound of the Knee-joint treated Antiseptically brought before the Clinical Society by Mr. Pick, and reported in THE LANCET of Oct. $16 \mathrm{th}$, reminds me of a somewhat similar case in my own practice, treated on a different principle. I am not about to dispute the value of the antiseptic mode of treatment; I would merely urge that its great superiority over other and simpler methods is, as yet, not proven. Certainly, as far as the practice of surgery in country districts is concerned, where we have the immense 